\title{
Dynamic Characteristics of an Offshore Wind Turbine with Tripod Suction Buckets via Full-Scale Testing
}

\author{
Yun-Ho Seo, ${ }^{1}$ Moo Sung Ryu, ${ }^{2}$ and Ki-Yong Oh $\mathbb{D}^{3}$ \\ ${ }^{1}$ Department of System Dynamics, Korea Institute of Machinery and Materials, Daejeon 34103, Republic of Korea \\ ${ }^{2}$ Korea Electric Power Research Institute, Daejeon 34056, Republic of Korea \\ ${ }^{3}$ School of Energy System Engineering, Chung-Ang University, Seoul 06974, Republic of Korea \\ Correspondence should be addressed to Ki-Yong Oh; kiyongoh@cau.ac.kr
}

Received 3 July 2019; Revised 9 February 2020; Accepted 2 March 2020; Published 30 March 2020

Academic Editor: Dan Selişteanu

Copyright (C) 2020 Yun-Ho Seo et al. This is an open access article distributed under the Creative Commons Attribution License, which permits unrestricted use, distribution, and reproduction in any medium, provided the original work is properly cited.

The dynamic characteristics of an offshore wind turbine with tripod suction buckets are investigated through finite element analysis and full-scale experiments. In finite element analysis, an integrated framework is suggested to create a simple yet accurate high fidelity model. The integrated framework accounts for not only the strain dependency of the soil but also for all dynamics in the seabed, including those of the soil, suction bucket skirt, and cap. Hence, the model accurately describes the coupling effect of translational and rotational motions of the seabed. The prediction results are compared to the experimental results obtained via full-scale testing in four stages during construction and in several operational conditions. The comparison shows that the stiffness of the suction bucket cap and strain dependency of the soil play a significant role in predicting natural frequency, suggesting that these two factors should be considered in finite element analysis for the accurate prediction of dynamic responses of an offshore wind conversion system. Moreover, dynamic analysis of the strain and acceleration measured during operational conditions shows that strain is more robust than acceleration with regard to the characterization of the overall dynamics of an offshore wind conversion system because the natural frequency of an offshore wind turbine is very low. It can be inferred that the measurement of strain is a more effective way to monitor the long-term evolution of dynamic characteristics. The suggested integrated framework and measurement campaign are useful not only to avoid conservatism that may incur additional costs during load calculation and design phases but also to establish an intelligent operation and maintenance strategy with a novel sensing technique.

\section{Introduction}

Renewable and sustainable energies are attractive alternatives for mitigating issues related to the consumption of fossil fuels, including the volatility of oil prices, emission of carbon dioxide, and aggravation of air quality due to fine dust emission. Among renewable and sustainable energies, offshore wind power shows a variety of advantages including high energy density, low turbulence, and low wind shear [1]. Technological advances are also making wind energy competitive from the economic perspective [2-9]. In 2018, 409 new offshore wind turbines were commissioned in Europe, which provided an additional capacity of $2,649 \mathrm{MW}$, and the cumulative capacity of wind farms was $18,499 \mathrm{MW}[10]$.
There are two trends for offshore wind power. One trend is the increase of turbine rated capacity. Most wind farms under construction are using turbines with capacities higher than $6 \mathrm{MW}$. The other trend is increasing the distance from the shore to mitigate concerns raised by civil complaints as well as to achieve better wind potential. For offshore wind farms under construction in Europe in 2018, the mean distance from the shore is $33 \mathrm{~km}$ [10]. However, the farther that a wind farm is from the shore, the deeper the water depth of its candidate site. The average water depth of European offshore wind farms under construction in 2018 is $27.1 \mathrm{~m} \mathrm{[10]}$. The long distance from the shore and deep water depth hinder the economic feasibility of wind farms.

To increase the economic feasibility of offshore wind farms, many studies have focused on substructures and 
foundations because the cost for these components accounts for $20-40 \%$ of the total cost, depending on water depth [11]. With regard to substructures, space frame substructures, including tripods and jacket structures, are the most promising. They provide sufficient strength and stiffness at a competitive cost in transitional water depths at which most new wind farms are permitted for installation nowadays. Regarding foundations, bearing capacity is the most important factor in supporting an offshore wind turbine. To estimate bearing capacity, soil-pile interaction should be exactly elucidated depending on types of foundations: gravitational type, pile type, and rigid bucket.

For the gravitational type, the deformation of bulk soil on the surface is of interest in the sense that the most interactions between the foundation and soil occur at the contact surface between the foundation and soil. However, this type is only feasible for shallow water because the construction cost is proportional to water depth and thus expensive for transitional water depths. Consequently, this type is no longer used for MW-class wind turbines installed in transitional water depths. For the pile type, the ratio of flexibility between soil and a pile is of interest because the ratio of flexibility governs soil-structure interaction [12]. Hence, the ratio of flexibility between soil and the pile is important to determine the specifications of the pile, including size and height [13]. Many current wind farms have been installed in transitional water depths with the pile type because of its proven reliability. Regarding the deep and rigid caisson type, interactions occur only below and beside the foundation. The shape of the foundation (aspect ratio) and soil properties are important to evaluate the influence on the interaction. If the foundation is very rigid compared to the soil, coupling of translational and rotational stiffness should be considered.

Interestingly, a suction bucket has the characteristics of both flexible pile and rigid caisson regarding the interaction with soil [14], making the design and construction more difficult and complex. Several factors affect the interaction between the soil and the suction bucket, including dimension, aspect ratio of a suction bucket, soil properties, and the ratio of flexibility between the soil and the suction bucket. Although designing suction buckets is difficult and complex, suction buckets become more promising than pile foundations in the transitional water depth because suction buckets are economic and offer simple and fast installation [15]. Moreover, suction buckets can help overcome several issues associated with the installation of the pile type including low level of vibration, noise, and suspended sediments.

Several studies have been conducted to deploy suction buckets on the foundations of offshore wind turbines $[16,17]$. Design procedures for the installation of suction buckets in sand and clay have been suggested [18, 19]. Experimental studies on the installation of suction buckets have been conducted for sand and clay to validate suggested models and provide appropriate parameters in models [20,21]. Bearing capacities and resistances of suction buckets under a variety of operational conditions have also been studied [22, 23]. Moreover, the effects of plasticity and cyclic loads on the behavior of suction buckets have been analyzed to observe operational performance and degradation of stiffness $[24,25]$. These intensive studies have elaborated the model accuracy of suction buckets and provided useful information for understanding soil-pile interactions. However, many of the suggested high fidelity models require heavy computational efforts to calculate the static and dynamic responses of offshore wind conversion systems (OWCSs) comprising offshore wind turbines, substructures, and foundations. These heavy calculation efforts hinder the use of these models in the design phases of commercial wind farms because hundreds of load calculations should be conducted in the actual design of substructures and foundations to ensure the reliability and safety of the OWCSs at a variety of operational conditions. Previous experimental studies have been conducted with laboratory model tests or reduced-scale field trials. Hence, uncertainty still exists with regard to the interapplicability of the results obtained from laboratory model tests, field trials with a reduced scale, and full-scale installations. Moreover, significant site-to-site variation of soil properties and the strain dependence of modulus of elasticity cause numerous difficulties and complications in the actual design and construction of a commercial wind farm.

Thus, it is essential to bridge the gap between theory and experiments as well as that between academic research and field applications and thereby mitigate concerns regarding uncertainty and increase prediction accuracy in the development phase of commercial offshore wind farms with multipod suction buckets. To this end, this study suggests a simple yet effective design procedure and its validation method. In particular, an efficient integrated framework is proposed to predict the dynamic responses of OWCSs. This framework also suggests a method of collaboration between civil engineering and mechanical engineering to design a commercial offshore wind farm.

From the civil engineering perspective, a suction bucket was designed in detail to provide sufficient bearing capacity for a selected offshore wind turbine based on an actual soil investigation, including the cone penetration test (CPT) and standard penetration test (SPT). Then, design parameters of the foundation were fed into a three-dimensional (3D) finite element model (FEM) to estimate the equivalent stiffness matrix of the seabed. This matrix accounts for the coupling effect between the translational and rotational motions of the seabed to enhance prediction accuracy. From the mechanical engineering perspective, dynamic analysis was conducted via a high fidelity $3 \mathrm{D}$ FEM of the OWCSs with the equivalent stiffness matrix of the seabed that was obtained via civil engineering as the boundary condition.

Two full-scale measurement campaigns were also conducted during the construction and operation. The dynamic characteristics were measured to validate the prediction of the integrated simulation framework when significant progress in construction was achieved. The forces of impact caused by a ship or aero/hydrodynamic excitation forces from winds and waves were used for the excitation of structures in four stages during construction. Moreover, a structural health monitoring (SHM) system was installed to 
measure the dynamic characteristics during operation. The data measured using the SHM system were also used for the validation of the integrated simulation framework and evolution of dynamic responses of the OWCS. A comparison between predicted and experimental results suggests that several important features should be accounted for to accurately predict the dynamic responses of the OWCSs, including the stiffness of the cap of the suction bucket and strain dependency of the modulus of elasticity of the soil.

\section{Integrated Simulation Framework}

Figure 1 shows a schematic of an integrated simulation framework for predicting the dynamic characteristics of an OWCS. Dynamic characteristics of the OWCS should be predicted to determine the specifications of the substructure in the design and load calculation phases because fundamental force frequencies (1P and $3 \mathrm{P}$ ) should be avoided in the first natural frequency of the OWCS during operation $[26,27]$. Hence, prediction accuracy is very important to secure the reliability and safety of OWCSs, given that the design lifespan of an OWCS is more than 20 years. The integrated framework proposed herein is separated into two parts. The first part is estimating a $6 \times 6$ stiffness matrix $\mathbf{K}_{\text {Seabed }}$ that represents the stiffness of the seabed including the soil and suction buckets. The method for estimating the stiffness matrix $\mathbf{K}_{\text {Seabed }}$ is described in detail through experiments and simulation in Section 2.1. The second part is predicting the dynamic characteristics of the OWCS and its substructure with a simple yet effective modeling method constrained by boundary conditions from the stiffness matrix $\mathbf{K}_{\text {Seabed }}$. The modeling of the wind turbine system and substructure is described in detail in Section 2.2.

2.1. Soil and Suction Buckets. Figure 2 shows the procedure for estimating the stiffness matrix $\mathbf{K}_{\text {Seabed }}$, accounting for the stiffness of the soil and suction buckets. Hence, the stiffness matrix $\mathbf{K}_{\text {Seabed }}$ represents the dynamic characteristics of the seabed connected to a substructure as a unified model, as shown in Figure 1.

In step 1, soil characteristics of the installation location of the OWCS were investigated. The candidate site is located near a breakwater in a southwestern sea area of the Korean Peninsula. The exact location is $35^{\circ} 58^{\prime} 19.43^{\prime \prime}$ North (latitude) and $126^{\circ} 30^{\prime} 53.39^{\prime \prime}$ East (longitude). The mean sea level of the site is $13.6 \mathrm{~m}$. This site was selected as a testbed of the OWCS to establish the design procedure and criteria for the commercial development of an offshore wind farm with a multipod substructure with suction buckets.

The soil investigation, including the CPT and SPT, was conducted through a site survey. Note that site surveys for conducting the CPT and SPT are indispensable in the design phase for the characterization of the actual soil properties of the site because soil properties are highly nonlinear and vary by site. This nonlinearity includes strain dependency, different dynamic behavior depending on type of soil (i.e., sand or clay), grain size, and pore water pressure. This complexity is the main reason for developing a standard procedure and code of analysis in the design phase of an offshore wind farm. Bearing resistance, friction resistance, and pore water pressure were measured through CPT, whereas soils were sampled at depth through SPT. The tests were conducted up to a depth of $10.7 \mathrm{~m}$.

In step 2, soil properties of each layer were estimated through laboratory experiments with soil samples collected at depth. Table 1 shows soil properties estimated through laboratory experiments. The results show that the site consists of three layers, with each layer featuring different soil properties. Sand is dominant in the first and third layers, whereas clay is dominant in the second layer (see Table 1).

Using an empirical equation, Young's modulus $E$, which is a key parameter that describes soil dynamics, can be estimated with the measured cone tip bearing resistance $q_{c}$ over depth. Different empirical equations should be applied to estimate Young's modulus $E$ for sand and clay because of inherent differences between various types of soils.

To estimate the initial tangent shear modulus $G_{\max }$ for the sand layers, 14 empirical models were used. Three models [28-30] directly calculated the initial tangent shear modulus $G_{\max }$. Three models $[29,31,32]$ first calculated Young's modulus $E$; then, this value was converted to the initial tangent shear modulus $G_{\max }$ as

$$
G_{\max }=\frac{E}{2(1+v)} \text {. }
$$

Eight models [33-40] first calculated the velocity of a shear wave traveling $V_{s}$ through soil with the cone tip bearing resistance $q_{c}$; then, this value was converted to the initial tangent shear modulus $G_{\max }$ as

$$
G_{\max }=\gamma_{d} V_{s}^{2} \text {. }
$$

These values were calibrated with the ratio of the secant shear modulus and initial tangent shear modulus, i.e., $\left(G / G_{\max }\right)$, with respect to the shear strain considering that Young's (shear) modulus of the soil significantly depends on (shear) strain. The ratio of $\left(G / G_{\max }\right)$ with respect to shear strain was obtained from laboratory experiments on samples from the Saemangeum Embankment, which is located near the installation site of OWCS [41] (Figure 3(a)).

To estimate Young's modulus $E$ for the clay layer, six empirical models were used. One model [43] calculated the initial tangent shear modulus $G_{\max }$, whereas the remaining five models [44-48] calculated the velocity of a shear wave traveling through soil $V_{s}$ with the cone tip bearing resistance $q_{c}$; subsequently, the estimated velocity was converted into the initial tangent shear modulus $G_{\max }$ using equation (2). All values were calibrated with the ratio of the secant shear modulus and the initial tangent shear modulus $\left(G / G_{\max }\right)$ with respect to the shear strain to account for strain dependency. Shear strain-shear modulus curves suggested by Vucetic and Dobry [42] were used in this study to calculate Young's modulus $E$ of the clay layer (Figure 3(b)). A plasticity index (PI) of 30 was used for calibrating the modulus because the PI of the clay layer was 29.7 (see Table 1). 


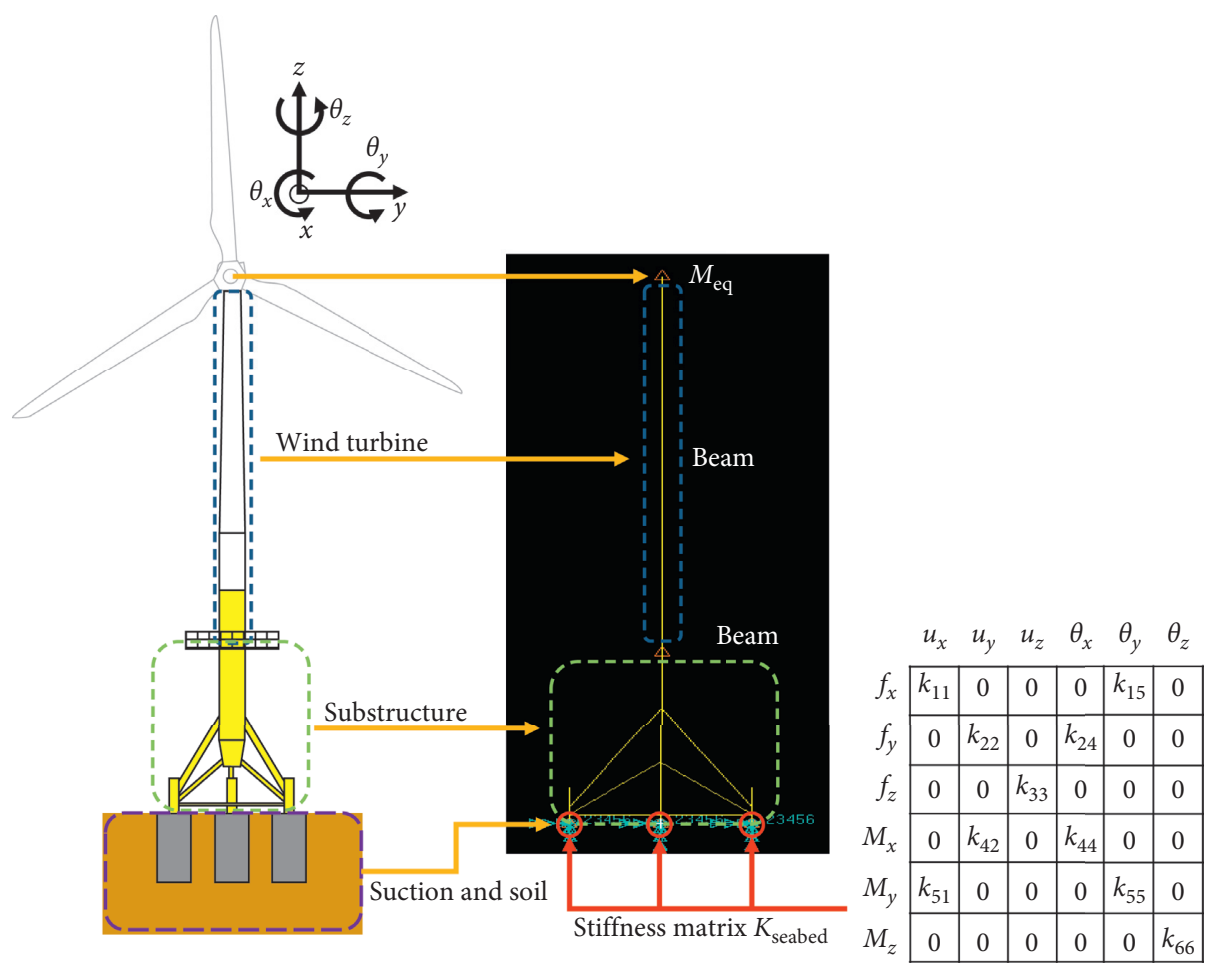

FIgURE 1: Simplified model for an OWCS with a tripod suction buckets.

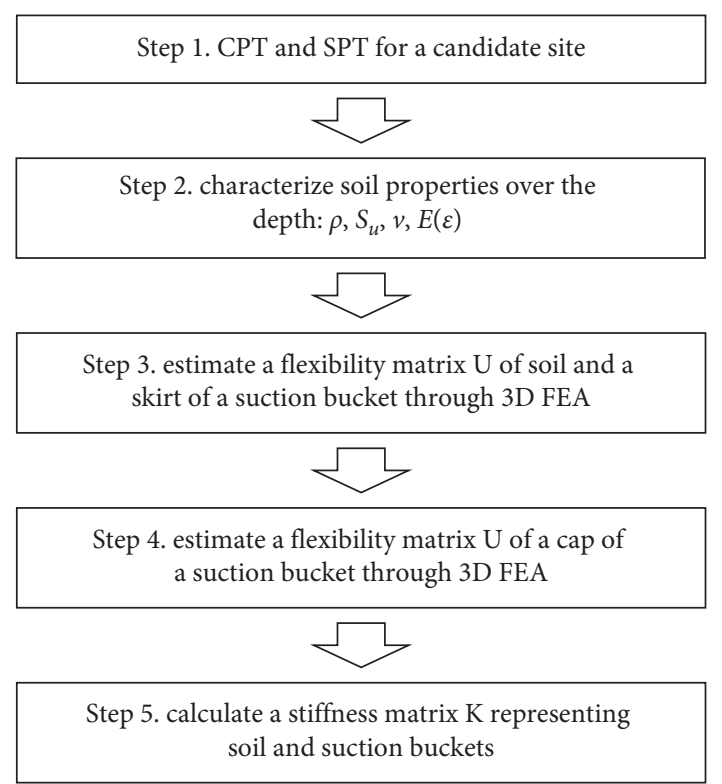

Figure 2: Procedure for estimating a stiffness matrix $\mathbf{K}_{\text {Seabed }}$ representing soil and suction buckets.

Finally, all estimated values from different empirical equations, excluding the maximum and minimum values for each layer, were averaged and converted into Young's modulus $E$ with respect to strain (Table 2). Table 2 shows that Young's modulus $E$ significantly decreases with an increasing strain $\varepsilon$, suggesting that the strain dependency of Young's modulus $E$ should be considered for soil that supports OWCSs because the large blades in OWCSs
TABLE 1: Soil properties at the site of installation.

\begin{tabular}{lcccccc}
\hline Depth $(\mathrm{m})$ & Soil type & $\gamma_{d}\left(\right.$ ton $\left./ \mathrm{m}^{3}\right)$ & $S_{u}(\mathrm{kPa})$ & $\phi\left(^{\circ}\right)$ & $v$ & PI \\
\hline $0-2.5$ & Sand & 19.0 & 8 & 25 & 0.35 & - \\
$2.5-8.3$ & Clay & 18.5 & 45 & 0 & 0.40 & 29.7 \\
$8.3-10.7$ & Sand & 19.0 & 15 & 36 & 0.35 & - \\
\hline
\end{tabular}

$\gamma_{d}, S_{u}, \phi, \nu$, and PI denote unit weights for zero water content, undrained shear strength, internal friction angle, Poisson's ratio, and the plasticity index.

intensify the aerodynamic force acting on supporting structures, through which significant deformation might occur; other structures installed in the ocean are designed such that the aerodynamic force is minimized.

In step 3, 3D finite element analyses (FEAs) were conducted to elucidate soil-structure interaction between the soil and the skirt of suction buckets. This 3D FEA accounts for multilayer characteristics with different types of soil over depth. Different values of Young's modulus $E$ were also used in case studies to account for the strain dependency of the soil. Then, a flexibility matrix $\mathbf{A}_{\text {soil+suc. }}$ was calculated for an integrated dynamic analysis, where the subscript suc. denotes the skirt of the suction bucket. Hence, $\mathbf{A}_{\text {soiltsuc. }}$ is the flexibility matrix of the skirt of the suction bucket embedded in soil. Note that this matrix does not account for the flexibility of the cap of suction buckets. The flexibility of the cap is estimated in the next step.

Regarding 3D FEA, an elaborate model describing the interaction between soil and the skirt was built with hexagonal elements (Figure 4). The diameter and length of the suction buckets are $6 \mathrm{~m}$ and $12 \mathrm{~m}$, respectively, and the thickness of the skirt is $19 \mathrm{~mm}$. The following properties of 


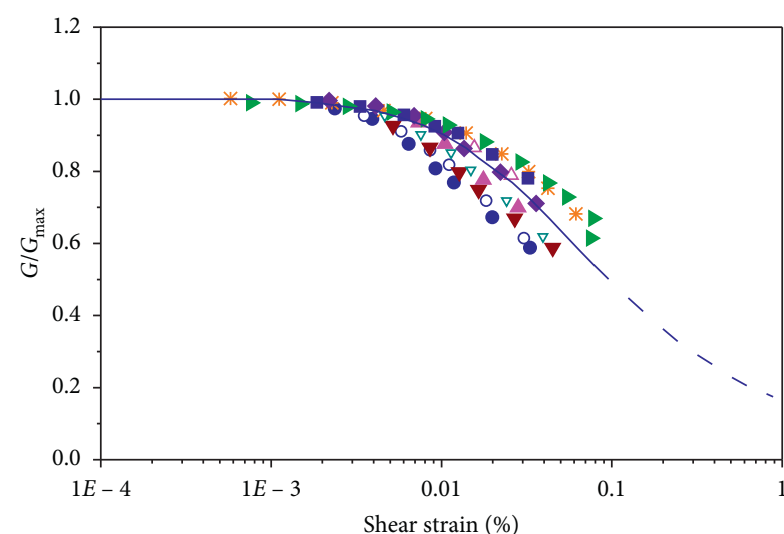

- SM_Dr70\%_RC $(25 \mathrm{kPa})$

。 SM_Dr70\%_RC $(50 \mathrm{kPa})$

A SM_Dr70\%_RC $(100 \mathrm{kPa})$

$\triangle$ SM_Dr70\%_RC $(200 \mathrm{kPa})$

* SM_Dr70\%_RC $(400 \mathrm{kPa})$

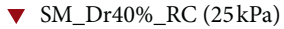

(a)

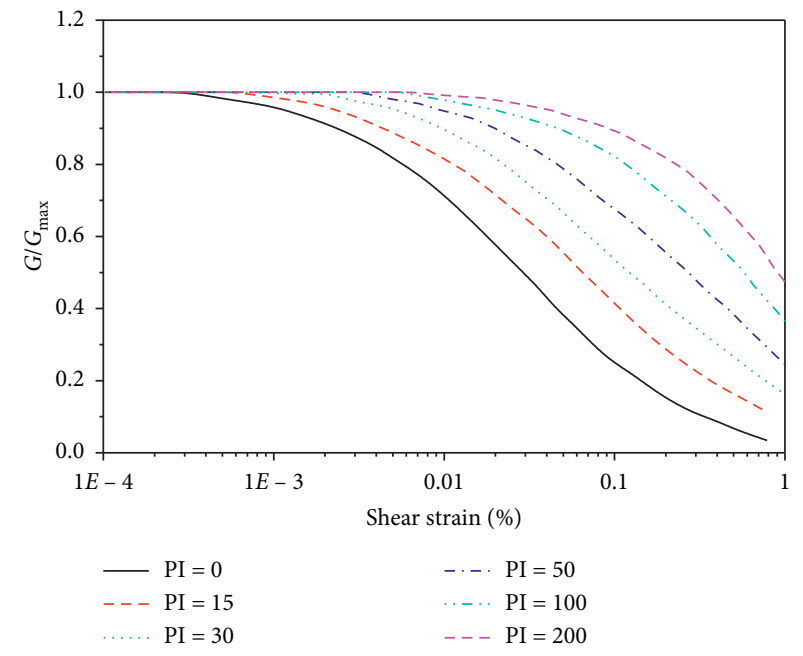

(b)

Figure 3: Normalized shear modulus over shear strain and PI for (a) soil obtained from Saemangeum Embankment [41] and (b) soil of clay suggested in [42].

TABLE 2: Elastic modulus of each layer with respect to deformation.

\begin{tabular}{llcc}
\hline & \multicolumn{3}{c}{ Young's modulus E $(\mathrm{kPa})$} \\
\hline Strain $\mathcal{E}(\%)$ & $<10^{-3}$ & 0.01 & 0.1 \\
Sand (upper layer) & 17700 & 16100 & 8700 \\
Clay & 18300 & 15000 & 9300 \\
Sand (lower layer) & 53300 & 48500 & 26100 \\
\hline
\end{tabular}

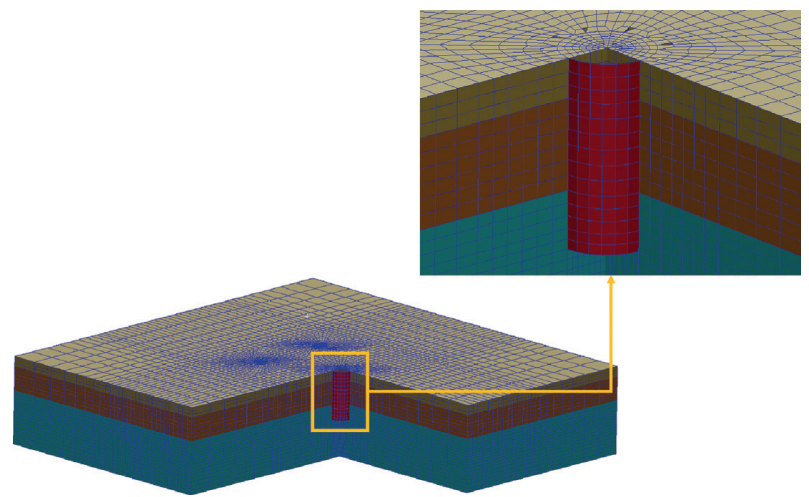

FIGURE 4: Three-dimensional finite element model for soil and a skirt of a suction bucket.

steel were used because the suction bucket is made of steel: Young's modulus $=210 \mathrm{GPa}$, Poisson's ratio $=0.29$, and density $=7850 \mathrm{~kg} / \mathrm{m}^{3}$. Boundary conditions of all the surfaces, except the top surface, were clamped to represent nondeformed locations. Further details on the dimensions of the suction buckets are not described herein because they are beyond the scope of this study.

This $3 \mathrm{D}$ finite element model was used to calculate a $6 \times 6$ flexibility matrix $\mathbf{A}_{\text {Soil+Suc.s }}$ [49], which is defined as

$$
\mathbf{A}_{\text {Soil+Suc.s }}=\left[\begin{array}{cccccc}
a_{11} & a_{12} & a_{13} & a_{14} & a_{15} & a_{16} \\
a_{21} & a_{22} & a_{23} & a_{24} & a_{25} & a_{26} \\
a_{31} & a_{32} & a_{33} & a_{34} & a_{35} & a_{36} \\
a_{41} & a_{42} & a_{43} & a_{44} & a_{45} & a_{46} \\
a_{51} & a_{52} & a_{53} & a_{54} & a_{55} & a_{56} \\
a_{61} & a_{62} & a_{63} & a_{64} & a_{65} & a_{66}
\end{array}\right],
$$

where $a_{i j}$ is a flexibility influence coefficient. The flexibility of a suction bucket embedded in soil is similar to that of passive joints [50], suggesting that the flexibility matrix $\mathbf{A}$ includes a number of zero elements as

$$
\mathbf{A}_{\text {Soil+Suc.s }}=\left[\begin{array}{cccccc}
a_{11} & 0 & 0 & 0 & a_{15} & 0 \\
0 & a_{22} & 0 & a_{24} & 0 & 0 \\
0 & 0 & a_{33} & 0 & 0 & 0 \\
0 & a_{42} & 0 & a_{44} & 0 & 0 \\
a_{51} & 0 & 0 & 0 & a_{55} & 0 \\
0 & 0 & 0 & 0 & 0 & a_{66}
\end{array}\right] .
$$

A basic assumption in this approach is that force in the $x$ $(y)$ direction and moment in the $y(x)$ direction mainly contribute to deformation in the $x(y)$ direction. In a similar manner, force in the $x(y)$ direction and moment in the $y(x)$ direction mainly contribute to angular displacement in the $y$ $(x)$ direction. Note that a coupling effect between translational and rotational degrees of freedom (DOF) is an actual physical phenomenon in the response of the suction bucket. Therefore, the coupling effect should be considered to accurately evaluate equivalent soil stiffness. Each element of the flexibility matrix $\mathbf{A}$ is calculated by 


$$
\mathbf{U}=\mathbf{A F},
$$

where $\mathbf{U}$ and $\mathbf{F}$ denote a displacement vector expressed as $\left[\begin{array}{llllll}u_{x} & u_{y} & u_{z} & \theta_{x} & \theta_{y} & \theta_{z}\end{array}\right]^{\mathrm{T}}$ and a force vector expressed as

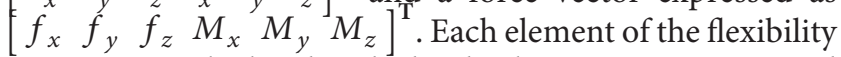
matrix $\mathbf{A}$ is calculated with the displacement vector $\mathbf{U}$ and force vector $\mathbf{F}$ when a unit force (or unit moment) is applied. Specifically, $a_{11}$ and $a_{51}$ are calculated with responses $u_{x}$ and $\theta_{y}$, respectively, by $3 \mathrm{D}$ FEA when a unit force $\left(f_{x}=1\right)$ is applied with other zero forces and moments. In a similar manner, $a_{24}$ and $a_{44}$ are calculated with responses $u_{y}$ and $\theta_{x}$ by $3 \mathrm{D}$ FEA when a unit moment $\left(M_{x}=1\right)$ is applied with other zero forces and moments.

In step 4, 3D FEAs were conducted to estimate the flexibility matrix $\mathbf{A}_{\text {suc. }}$ of the cap, where the subscript suc. ${ }_{c}$ denotes the cap of the suction bucket. The diameter of the cap experiences significant changes over depth, whereas the diameter of a mono pile remains unchanged. This significant change of shape occurs in the suction bucket to provide sufficient bearing capacity with relatively small length of the skirt, whereas the mono pile generates a large bearing force with a long length of the pile. This significant change in diameter may induce stress concentration and local flexibility even if the cap is reinforced by many stiffeners. 3D FEA is an efficient solution for calculating the flexibility matrix $\mathbf{A}_{\text {suc. }}$ because of the complex design of the cap. The cap was modeled as combination of 2D plates and an edge of the cap was assumed to be clamped in the sense that the edge connecting the cap with the skirt is much stiffer than others (Figure 5(a)). Then, a unit force or a unit moment in three directions was applied to calculate the $6 \times 6$ flexibility matrix $\mathbf{A}_{\text {suc. }_{\text {. }}}$ with deformation of the cap (Figures 5(b) and 5(c)).

In step 5, an equivalent flexibility matrix $\mathbf{A}_{\text {Seabed }}$ representing the flexibility of soil and the suction bucket is calculated as

$$
\mathbf{A}_{\text {Seabed }}=\mathbf{A}_{\text {Soil }+ \text { Suc. } ._{\text {s }}}+\mathbf{A}_{\text {suc. }_{c}} .
$$

This calculation can be explained similar to the case of two spring elements connected in series. One spring represents the stiffness of the soil and the skirt, and the other represents that of the cap. Finally, the equivalent stiffness matrix $\mathbf{K}_{\text {Seabed }}$ of the seabed can be calculated by matrix inversion as

$$
\mathbf{K}_{\text {Seabed }}=\mathbf{A}_{\text {Seabed }}^{-1} \text {. }
$$

This stiffness matrix was used as boundary conditions for a substructure as mentioned earlier.

2.2. Wind Turbine and Substructure. This study modeled the WinDS3000 TC-2 (Doosan Heavy Industries \& Construction, South Korea) wind turbine with a tripod substructure. WinDS3000 TC-2 is a $3 \mathrm{MW}$ offshore wind turbine with blades having a diameter of $100 \mathrm{~m}$. Based on the specifications of WinDS3000, which are provided by Doosan Heavy Industry \& Construction, the substructure was designed to prevent natural frequencies of the entire system from operational frequencies. Note that specifications of the wind turbine cannot be changed depending the site because turbine manufacturers require reissue of certificates when any specification of a wind turbine is changed [27]. Table 3 describes the dimensions of the tower and the tripod substructure in detail.

$\mathrm{GH}$ Bladed (DNV GL) was used to predict natural frequencies of the OWCS. A tube-shaped tower and a substructure were modeled using beam elements. An assembly of a nacelle, a hub, and blades can be modeled as a point mass. The assembly weighs 186 tons; the nacelle, hub, and blades weigh 128,28 , and 10 tons, respectively. Local flexibility of the blades, tower, and nacelle is negligible because a shape change in the tower or nacelle is small and blades of MW-class OWCS have sufficient stiffness with a sole natural frequency of above $0.6 \mathrm{~Hz}$ [51]. The substructures were designed as tripod suction buckets because the cost analysis for the offshore meteorological tower, Herald of the Meteorological and Oceanographic Special Research Unit (HeMOSU)-2, confirmed that the construction cost of tripod suction buckets was half of that of jacket piles, for the same seabed geology, construction, transportation, and supply chain in South Korea [26]. Note that the mean sea level for the candidate site of a $100 \mathrm{MW}$ wind farm is around $20 \mathrm{~m}$, meaning that gravity or monopole types are not economically feasible [52]. The pile type also gives rise to several environmental issues during construction, including vibration, noise, and suspended sediments. Moreover, the construction of HeMOSU-2 took only $6 \mathrm{~h}$, whereas that of HeMOSU-1, in which jacket piles were used, took two months for the installation [53]. The properties of steel described in Section 2.1 were used for the tower and substructure.

The effect of added mass was considered for the submerged substructure, which is defined as the substructure from the depth of the seabed to the depth of the mean sea level because the water added mass has a significant influence on the natural frequencies and mode shapes of a multipod substructure [54]. The inner space of the tubeshaped element below the sea level is filled by seawater and the outer surface is also in contact with seawater, suggesting that the amount of added mass is exactly related to the deformation shape of an element. However, the lowest mode deformation of an element in the finite element analysis can be assumed to be only translational. Therefore, added mass of the inner and the outer water can be set by the area of the element [55].

\section{Measurement Campaign}

3.1. Measurement under Construction. The evolution of dynamic responses was measured during the construction of the $3 \mathrm{MW}$-class OWCS. The measurement framework consisted of four stages, as shown in Figure 6. The natural frequency was measured at each stage when significant progress was achieved during construction. Specifically, the natural frequency was measured after completing the installation of tripod suction buckets at stage I (Figure 6(a)) and after completing the installation of bottom and middle towers at stage II (Figure 6(b)). In stage III, the natural frequency was measured after completing the installation of 


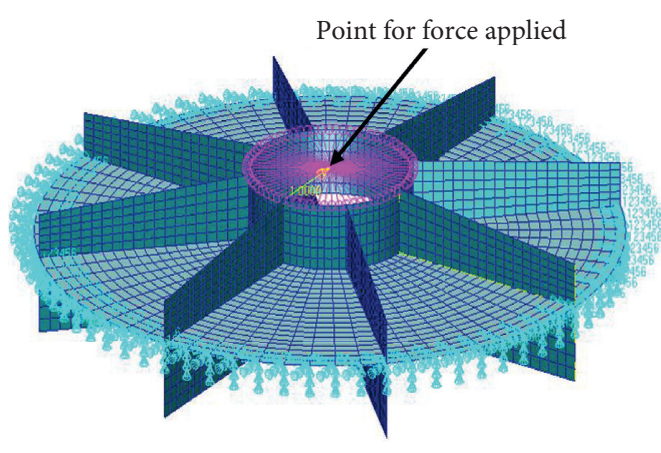

(a)

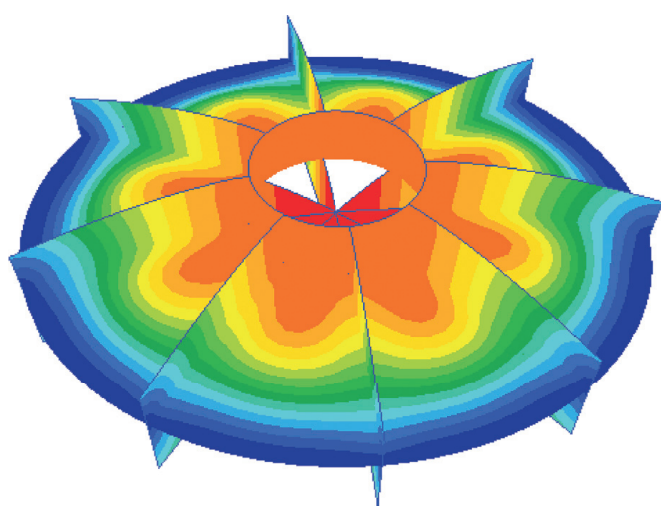

(c)

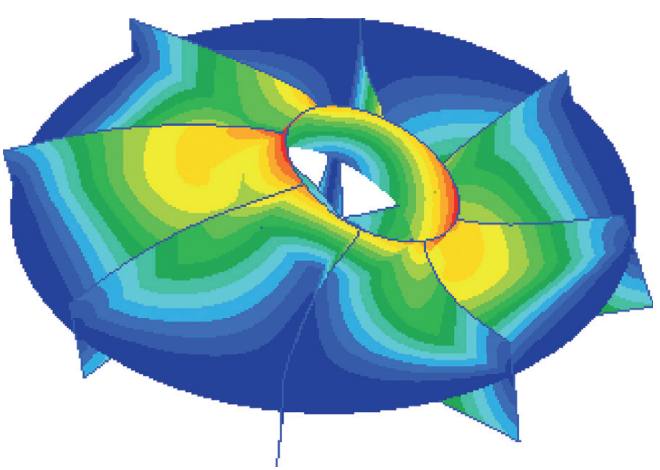

(b)

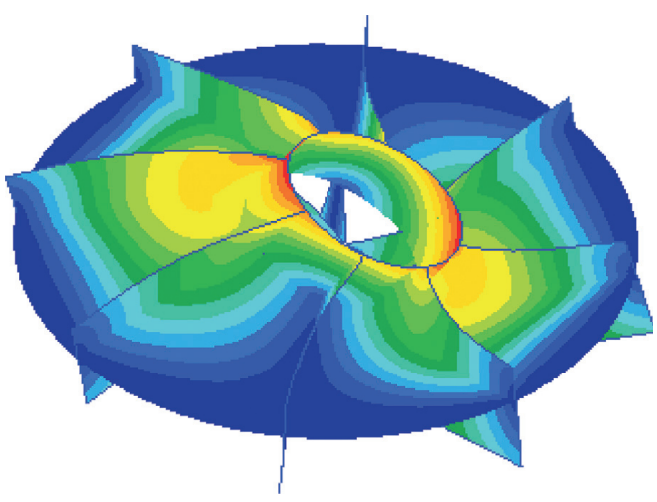

(d)

FIgURE 5: Finite element analysis results for calculating the flexibility matrix $\mathbf{A}_{\text {suc. }}$ of a cap of a suction bucket: (a) finite element model with the point force applied; relative displacement of the cap for (b) unit horizontal force, (c) unit vertical force, and (d) unit horizontal moment.

TABle 3: Dimensions of the OWCS model.

\begin{tabular}{lr}
\hline Maximum diameter of the tower & $4.5 \mathrm{~m}$ \\
Minimum diameter of the tower & $3.07 \mathrm{~m}$ \\
Length of the tower & $58.5 \mathrm{~m}$ \\
Maximum thickness of the tower walls & $46 \mathrm{~mm}$ \\
Minimum thickness of the tower walls & $18 \mathrm{~mm}$ \\
Maximum diameter of the main substructure & $4.5 \mathrm{~m}$ \\
Minimum diameter of the main substructure & $3.0 \mathrm{~m}$ \\
Length of the main substructure & $24.9 \mathrm{~m}$ \\
Maximum thickness of the main substructure & $54 \mathrm{~mm}$ \\
Minimum thickness of the main substructure & $30 \mathrm{~mm}$ \\
Maximum diameter of the supporting structure & $1.2 \mathrm{~m}$ \\
Minimum diameter of the supporting structure & $0.4 \mathrm{~m}$ \\
Maximum thickness of the supporting structure & $30 \mathrm{~mm}$ \\
Minimum thickness of the supporting structure & $17.5 \mathrm{~mm}$ \\
Distance from the center of the substructure to the & $11.5 \mathrm{~m}$ \\
suction buckets &
\end{tabular}

the nacelle on top of the tower (Figure 6(c)). Finally, the natural frequency was measured at stage IV after completing the installation of the hub and three blades (Figure 6(d)).

Two accelerometers with a sensitivity of $10 \mathrm{~V} / \mathrm{g}$ were installed on the top of the transition piece to measure accelerations along two directions perpendicular to each other. Figure $7(\mathrm{~d})$ shows the installed accelerometers on the transition piece.

In the experiments, the structures were excited in two ways. In one, a ship was used to provide impact force on only the substructure at stage I, whereas in the other, natural excitation from winds and waves was used to structures under construction from stage II to stage IV. Note that natural exciting forces from winds and waves were not sufficient to excite only the substructure in stage I. Hence, a small ship of 6.6 ton was used to provide impact force to the substructure (Figure 7(c)) because impact force in the time domain is white noise in the frequency domain [56]. The ship slowly approached on landing ladder to excite a substructure (Figures $7(\mathrm{a})$ and $7(\mathrm{~b})$ ); then, the dynamic response was measured. In contrast, structures at stages II, III, and IV were excited sufficiently by natural wind and waves. Hence, the natural frequencies at stages II, III, and IV were determined by measuring acceleration and through subsequent spectral analysis.

3.2. Measurement during Operation. A SHM system was installed to observe long-term variations of the dynamic responses of the OWCS during operation, such as acceleration, strain, temperature, and sea level. The natural frequency of the OWCS with the substructure was calculated using measured accelerations and strains. To measure the accelerations, 10 accelerometers were installed at 5 locations on the tower of the OWCS along the vertical direction (Figure 8(a)). Two accelerometers were installed perpendicular to each other at different heights in each location. For each set, one accelerometer was aligned north-northwest (NNW), the main direction of wind at the site, whereas the 


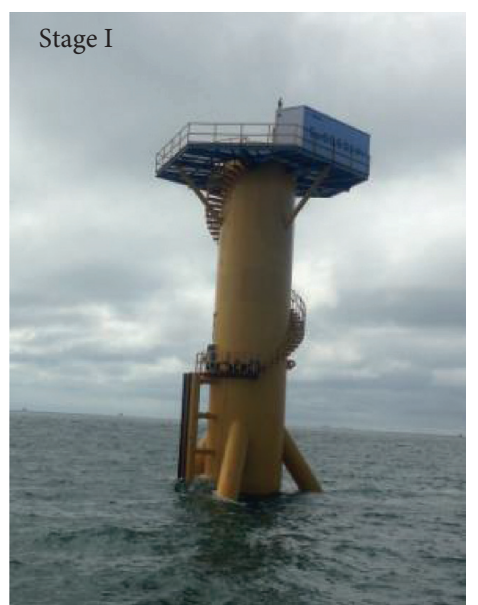

(a)

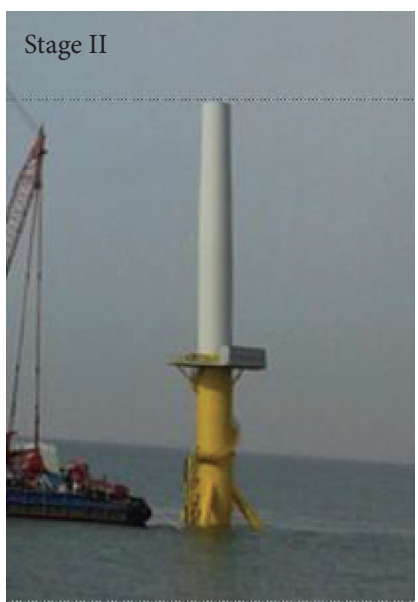

(b)

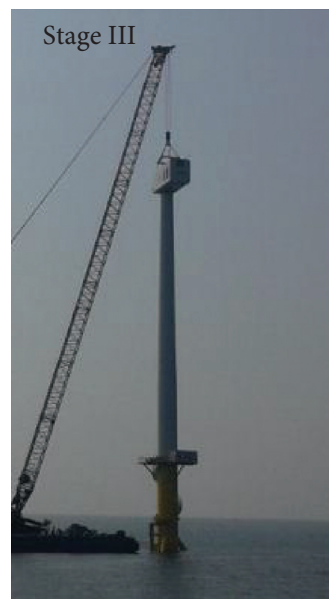

(c)

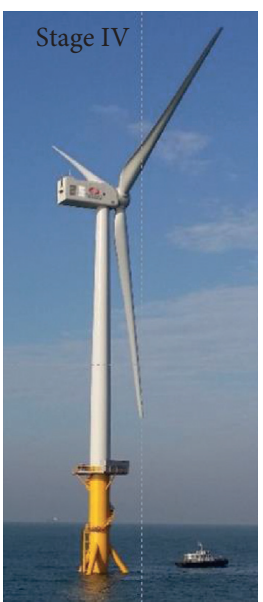

(d)

Figure 6: Measurement framework consisting of four stages during construction: (a) stage I (b) stage II, (c) stage III, and (d) stage IV.

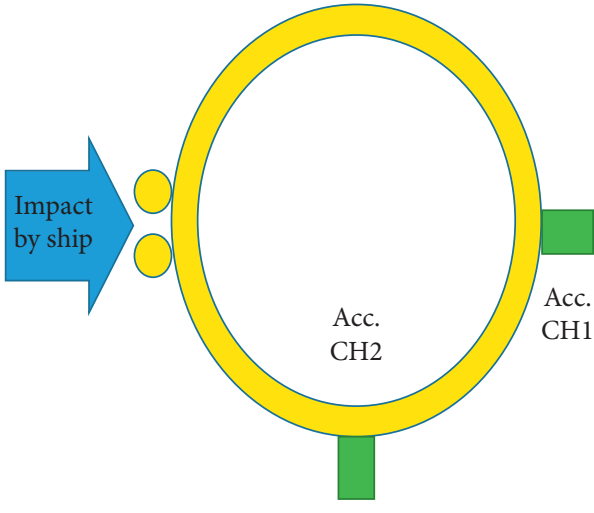

(a)

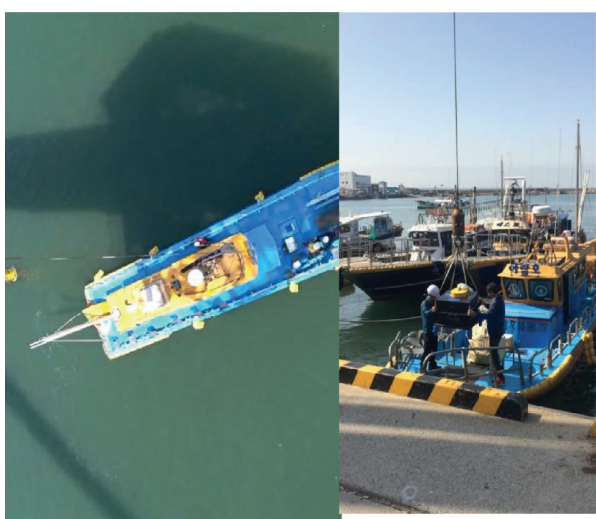

(c)

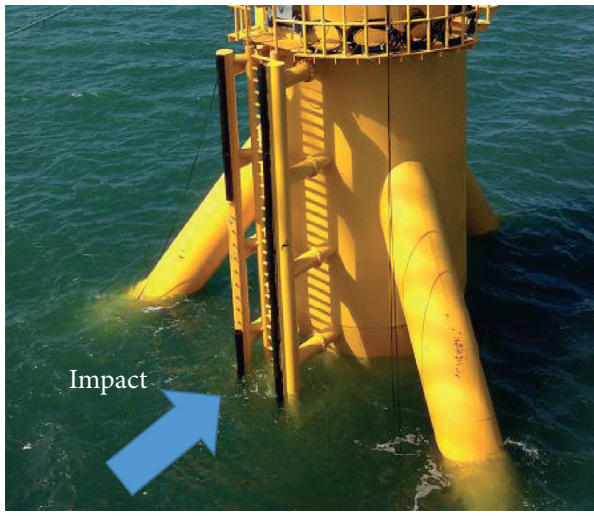

(b)

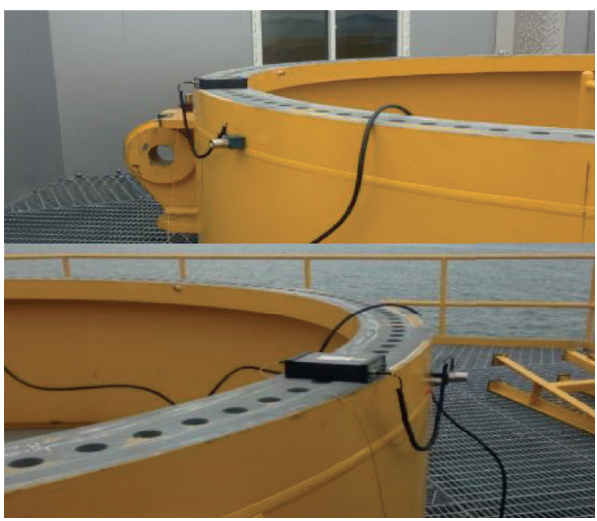

(d)

Figure 7: Impact tests only with substructure: a schematic diagram with (a) a top view and (b) an isometric view; (c) a ship used to induce impact force on a substructure; (d) accelerometers installed in channel 1 (top) and channel 2 (bottom).

other accelerometer was aligned east-northeast (ENE), perpendicular to the main direction of wind (Figure $8(\mathrm{~b})$ ) [57]. In addition, 4 sets of strain gauges were installed near the transition piece between the offshore wind turbine system and the substructure to measure bending deformation. Two sets of strain gauges were installed $+0.5 \mathrm{~m}$ from the transition piece; one set was aligned NNW and the other was aligned ENE. Two other sets of strain gauges were installed at $-0.5 \mathrm{~m}$ from the transition piece. Each set of strain gauges is a full bridge type. 


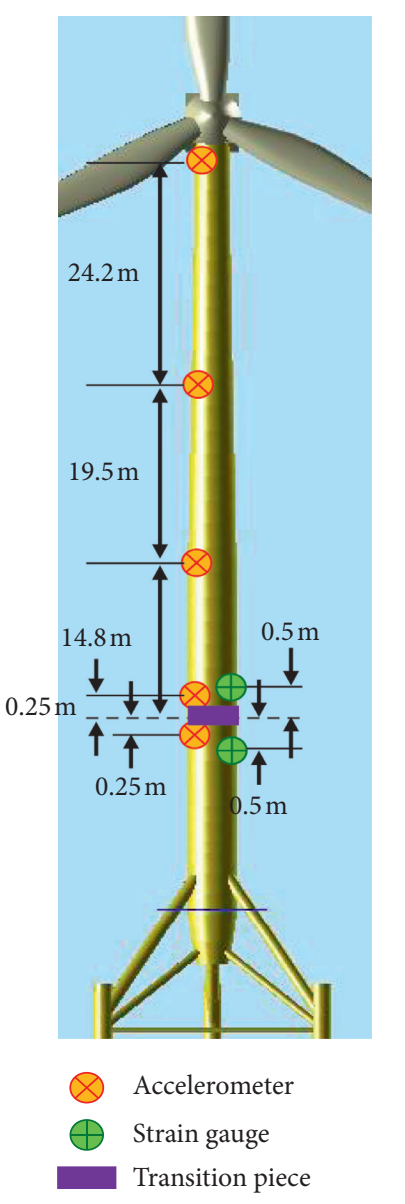

(a)

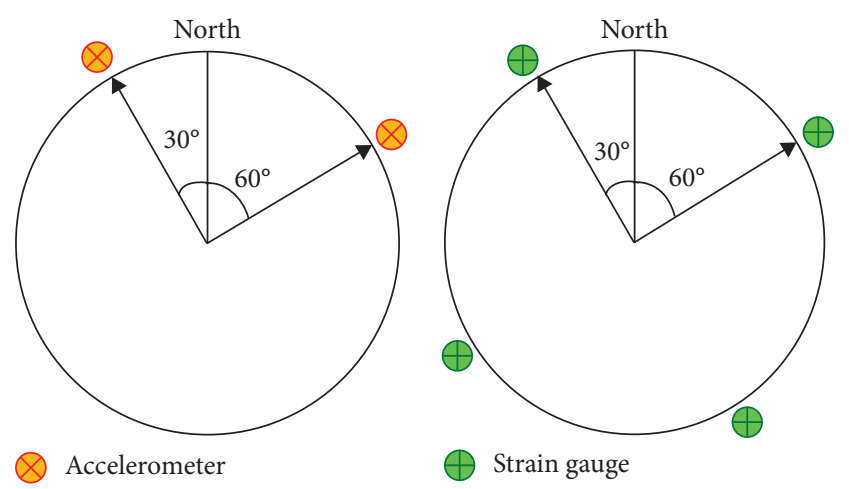

Strain gauge

FIGURE 8: Schematics of the structural health monitoring system: (a) installed locations of accelerometers and strain gauges along the vertical direction; installed locations of (b) accelerometers and (c) strain gauges along the horizontal direction.

\section{Results and Discussion}

\subsection{Dynamic Responses under Construction}

4.1.1. Stage I. The dynamic response of the tripod suction bucket measured at stage I was compared to that predicted from the integrated framework. To calculate the natural frequency based on an experiment performed at stage I, the measured acceleration (Figure 9(a)) with a record length of $11.8 \mathrm{~s}$ and sampling frequency of $256 \mathrm{~Hz}$ was converted to the frequency domain via fast Fourier transform (FFT). Then, the maximum peak in the spectrum was determined (Figure 9(b)). Hence, the resolution in the frequency domain for this data is $0.085 \mathrm{~Hz}$. Figure 9(a) shows the measured acceleration in the time domain, which follows the conventional transient response of a second-order system. This observation can be explained by the fact that the first mode is dominant for the tripod suction buckets embedded in the seabed; thus, it governs the overall dynamic behavior of the OWCS. The natural frequency of the tripod substructure determined through spectral analysis is $3.30 \mathrm{~Hz}$, as shown in Figure 9(b).
Four different cases were studied in the integrated framework to compare not only the effect of the cap of the suction bucket but also the strain dependency of the modulus (Table 4). In each case, the flexibility matrix $\mathbf{A}_{\text {soil+suc. }}$ accounts for only the stiffness of the soil and the suction skirt, as in many previous studies, whereas the flexibility matrix $\mathbf{A}_{\text {Seabed }}$ accounts for all stiffness components, including the soil, suction skirt, and suction cap. In case 1, strain is assumed to be less than $10^{-3}$ for all layers, whereas in case 2 , it is assumed to be approximately 0.01 for all layers. In case 3, the two uppermost layers are considered to experience a large strain of approximately 0.1 , whereas the deepest layer experiences a deformation of approximately 0.01 , assuming that a smaller deformation occurs in the deeper layer because of relatively high stiffness. In case 4 , a large deformation of approximately 0.1 is considered to occur for all layers.

The last two columns of Table 4 show the predicted natural frequencies (and the corresponding errors compared to the measured values that are given in parentheses) calculated with the corresponding flexibility matrix. 


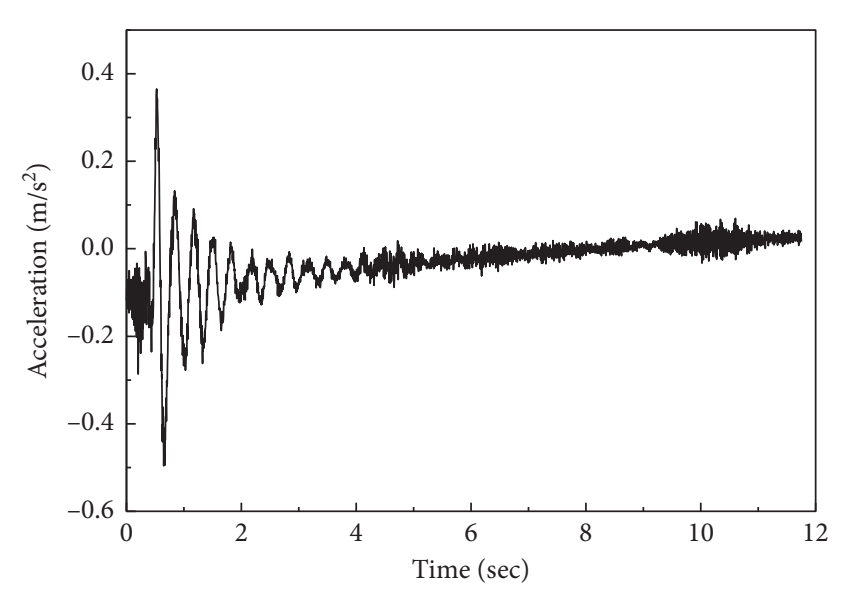

(a)

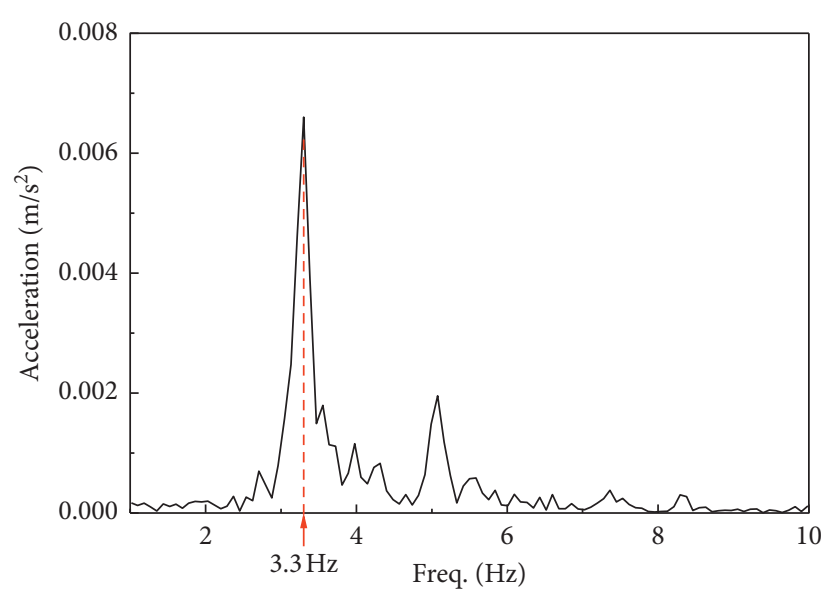

(b)

Figure 9: Measured acceleration data at stage I: (a) acceleration in the time domain and (b) spectrum in the frequency domain.

TABLE 4: Soil properties for case studies and natural frequencies (NF) predicted via the integrated simulation framework.

\begin{tabular}{|c|c|c|c|c|c|}
\hline \multirow{3}{*}{ Case number } & \multicolumn{3}{|c|}{ Young's modulus $E(\mathrm{kPa})$} & \multirow{2}{*}{\multicolumn{2}{|c|}{$\begin{array}{c}\text { Natural frequency }(\mathrm{Hz}) \text { (error } \\
\text { w.r.t. measurement \%) } \\
\text { Flexibility matrix }\end{array}$}} \\
\hline & \multirow{2}{*}{ Sand (upper layer) } & \multirow{2}{*}{ Clay } & \multirow{2}{*}{ Sand (lower layer) } & & \\
\hline & & & & 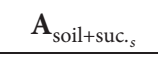 & $\mathbf{A}_{\text {Seabed }}$ \\
\hline 1 & 17700 & 18300 & 53300 & $4.30(30.3)$ & $3.77(14.2)$ \\
\hline 2 & 16100 & 15000 & 48500 & $4.21(27.6)$ & $3.71(12.4)$ \\
\hline 3 & 8700 & 9300 & 48500 & $3.98(20.6)$ & $3.40(3.03)$ \\
\hline 4 & 8700 & 9300 & 26100 & $3.57(8.18)$ & $3.24(1.82)$ \\
\hline
\end{tabular}

Remarkably, relatively large errors were encountered when only the flexibility matrix $\mathbf{A}_{\text {soil+suc. }}$ was considered. The errors ranged from $8.18 \%$ to $30.3 \%$ when only the flexibility matrix $\mathbf{A}_{\text {soil+suc. }}$ was considered, whereas they ranged from $1.82 \%$ to $14.2 \%$ when the flexibility matrix $\mathbf{A}_{\text {Seabed }}$ was considered. The errors attributed to this difference were at least double, i.e., $30.3 \%$ vs. $14.2 \%$ (case 1 ) or $8.18 \%$ vs. $1.82 \%$ (case 4), when the same modulus for each layer was applied. The analysis suggests that the stiffness of the cap plays a critical role in the prediction of dynamic responses of the substructure. Therefore, the contribution of the cap should be considered.

From the perspective of strain dependency, the error could be reduced by considering larger deformations in soil. Specifically, the error between the measured and predicted values was $1.82 \%$ when the strain for all layers is assumed to be approximately 0.1 (case 4 with the flexibility matrix $\left.\mathbf{A}_{\text {Seabed }}\right)$, whereas the error between measurement and prediction was $14.2 \%$ when strain is assumed to be less than $10^{-3}$ (case 1 with the flexibility matrix $\mathbf{A}_{\text {Seabed }}$ ).

The analysis of the dynamic characteristics of the tripod substructure in stage I clearly shows that the stiffness of the cap and Young's modulus, which accounts for strain dependency [58], should be considered to accurately predict the dynamic response of the OWCS and its substructure.

4.1.2. Stages II to $I V$. The natural frequencies under construction during stages II to IV were also obtained from the measured acceleration under natural excitation from wind and waves. In stages II to IV, acceleration could be measured over a long period because these experiments were conducted under natural excitation, whereas stage I was conducted using an impact test with a ship. Therefore, analysis could be conducted with high resolution in the frequency domain. The accelerations excited by wind and wave were measured for a period of $125 \mathrm{~s}$ with a sampling frequency of $1707 \mathrm{~Hz}$, meaning that the frequency resolution at the analysis is $0.008 \mathrm{~Hz}$. Figure 10 shows results of spectral analyses for stages II to IV. These frequency spectra show one clear peak even though the structure is under natural excitation, suggesting that natural excitation from wind and waves was sufficient for determining the natural frequencies of the structure under construction.

Table 5 shows a comparison between the measured and predicted values of natural frequency. The measured values were compared with the predicted values for cases that showed the largest and smallest errors in stage I, namely, case 1 and case 4, respectively. Similar to the results obtained in stage I, case 4 showed smaller errors than case 1 . Moreover, the percentage errors of case 1 with the flexibility matrix $\mathbf{A}_{\text {soil+suc.s }}$ in stage II were much smaller than those in stage I. This observation suggests that the contribution of the equivalent stiffness of the seabed to the natural frequency of the OWCS during stage II was lesser than that at stage I. In a similar manner, the errors of case 4 with the flexibility matrix $\mathbf{A}_{\text {soil+suc.s }}$ in stages II, III, and IV decreased compared to those in stage I. The predicted results for case 4 also show 


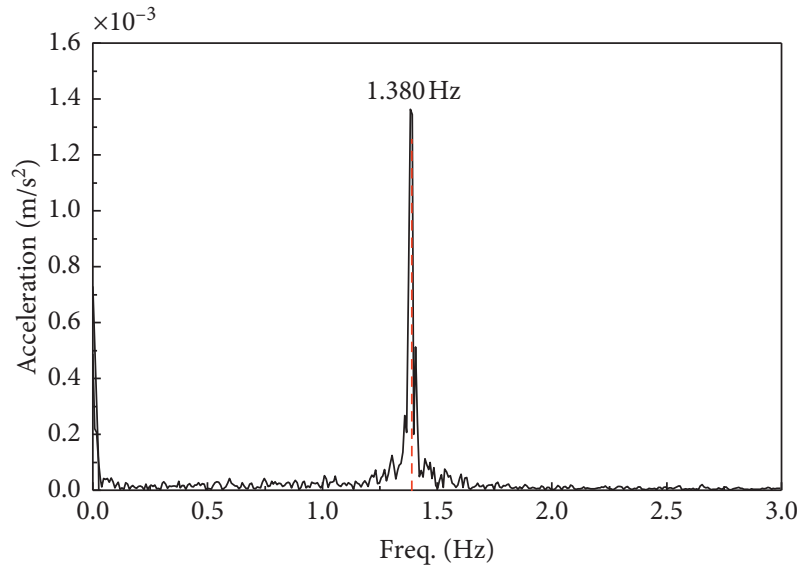

(a)

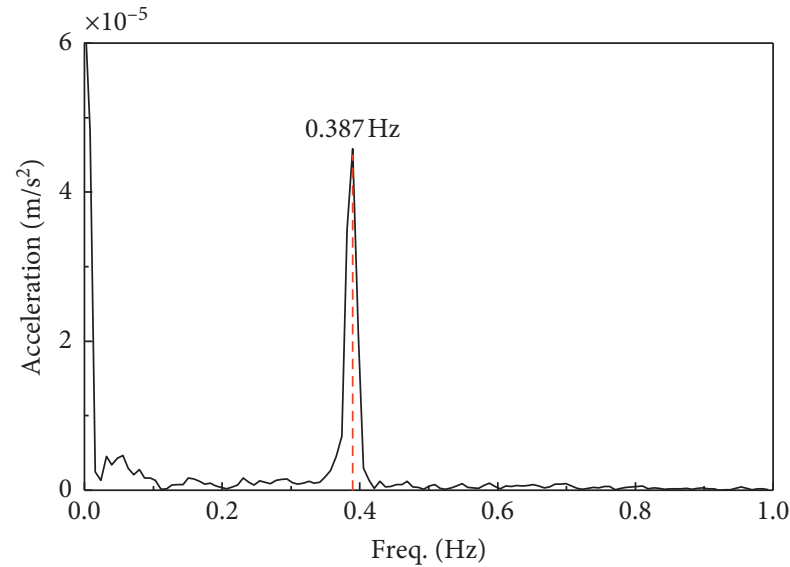

(b)

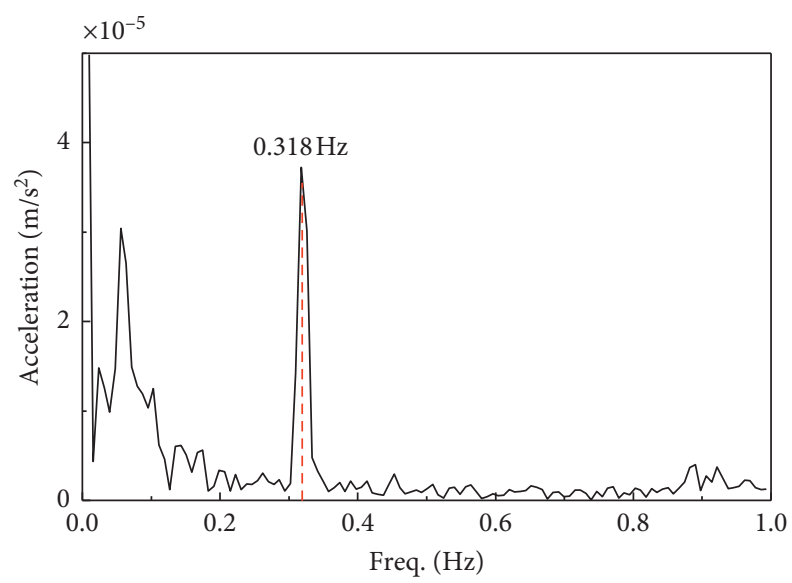

(c)

Figure 10: Spectral analyses of measured acceleration: (a) stage II, (b) stage III, and (c) stage IV.

TABLE 5: Comparison of measured and predicted values of natural frequency.

\begin{tabular}{|c|c|c|c|c|}
\hline & & \multicolumn{3}{|c|}{ Natural frequency $(\mathrm{Hz})$} \\
\hline & & Stage II & Stage III & Stage IV \\
\hline \multicolumn{2}{|l|}{ Measurement } & 1.380 & 0.387 & 0.318 \\
\hline \multirow{5}{*}{ Prediction } & $\begin{array}{l}\text { Case } 1 \text { with } \mathbf{A}_{\text {soiltsuc.s }_{\text {s. }}} \\
\text { (Error w.r.t. exp., \%) }\end{array}$ & $\begin{array}{c}1.530 \\
(10.87)\end{array}$ & $\begin{array}{l}0.391 \\
(1.03)\end{array}$ & $\begin{array}{l}0.334 \\
(5.03)\end{array}$ \\
\hline & Case 4 with $\mathbf{A}_{\text {soil }+ \text { suc. }}$ & 1.420 & 0.380 & 0.325 \\
\hline & (Error w.r.t. exp., \%) & $(2.89)$ & $(1.81)$ & $(2.02)$ \\
\hline & Case 4 with $\mathbf{A}_{\text {Seabed }}$ & 1.360 & 0.374 & 0.320 \\
\hline & (Error w.r.t. exp., \%) & $(1.45)$ & $(3.36)$ & $(0.94)$ \\
\hline
\end{tabular}

that the flexibility matrix $\mathbf{A}_{\text {Seabed }}$ shows more accurate predictions compared to the flexibility matrix $\mathbf{A}_{\text {soiltsuc. }}$. In conclusion, the model that accounts for the stiffness of the cap and strain dependency demonstrates increased prediction accuracy. The suggested elaborate model and method of predicting the dynamics of a substructure and foundation would be useful in predicting the long-term degradation of soil supporting the OWCS because soil degrades faster than the suction bucket and the substructure [59].
4.2. Dynamic Responses during Operation. Figure 11 shows the results of a spectral analysis of data obtained from a SHM system under idling (stop) and operational conditions. In the idling or stop conditions, the first natural frequency calculated was $0.318 \mathrm{~Hz}$ for the spectra of both acceleration and strain measured at various locations, further validating that the first natural frequency measured at stage IV is accurate. Moreover, the spectra did not exhibit location dependency between NNW and ENE. The spectra for ENE are omitted 


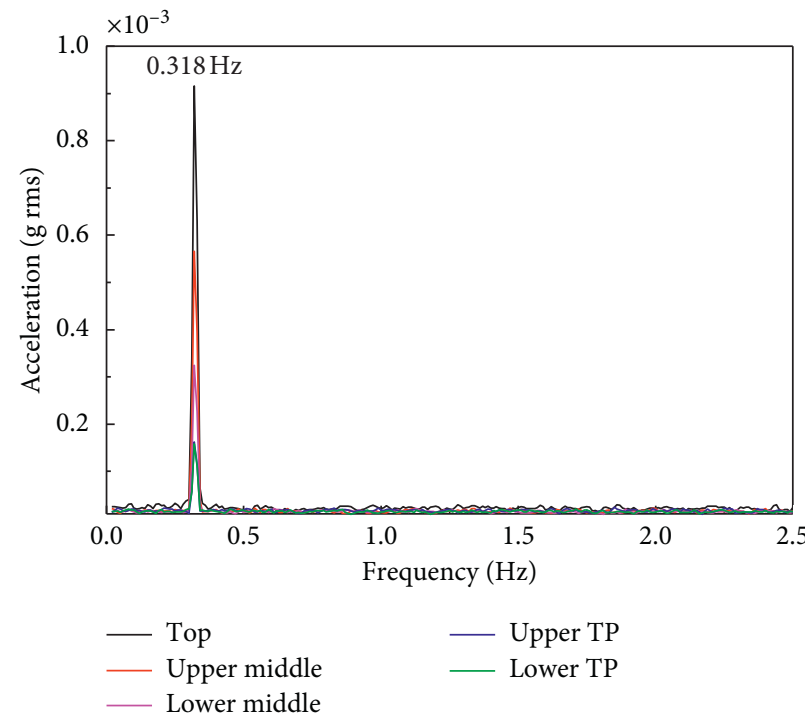

(a)

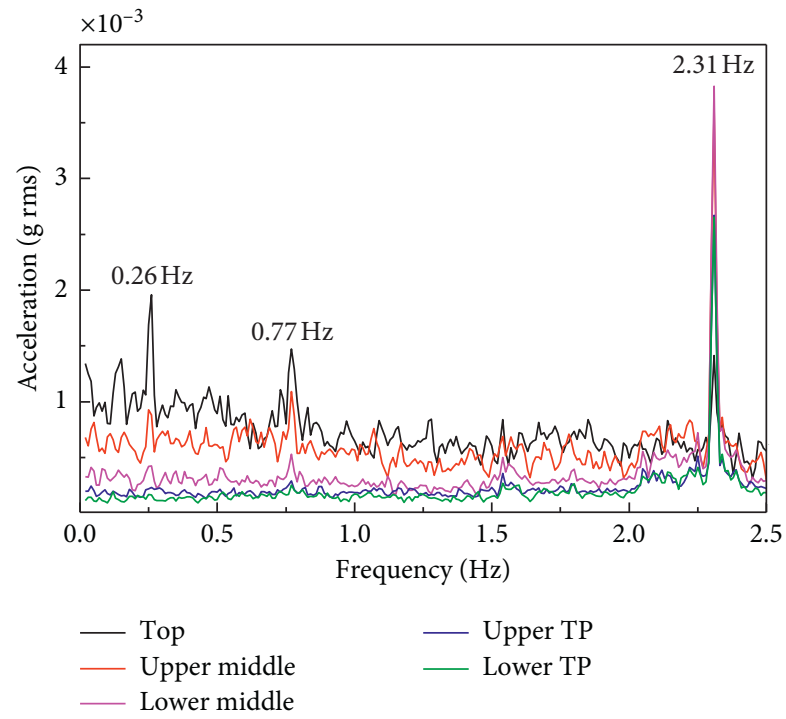

(c)

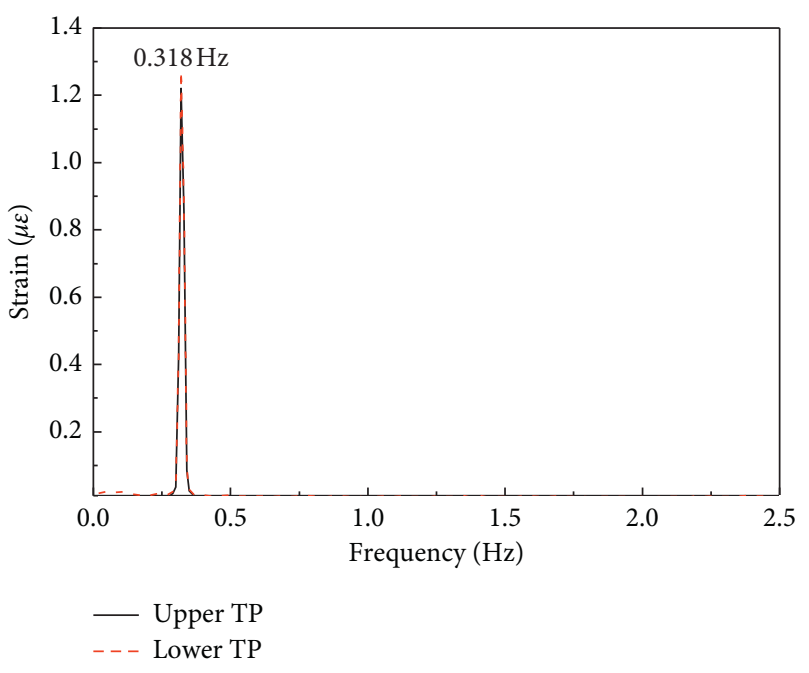

(b)

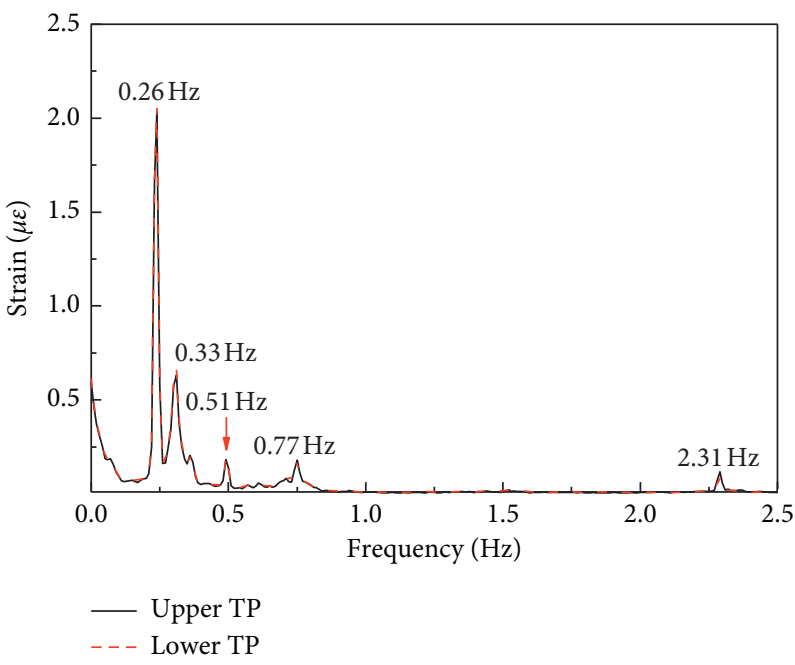

(d)

FIGURE 11: Spectral analyses of structural health monitoring system data along NNW direction under idling (stop) condition with (a) accelerometers and (b) strain gauges; rated operations measured in NNW direction with (c) accelerometers and (d) strain gauges.

herein for the sake of brevity. Hence, either of both measured data from accelerometers and strain gauges can be used to monitor natural frequency of the OWCS.

However, measured data under a rated production are different, as shown in Figures 11(c) and 11(d) for the wind turbines operating with a rotational speed of $15.4 \mathrm{rpm}$ $(0.26 \mathrm{~Hz})$. The natural frequency does not appear for the measured acceleration (Figure 11 11(c)). The spectra of acceleration simply show various peaks related to $1 \mathrm{P}$ (rotational speed), 3P (blade passing component), and their harmonics. In contrast, the natural frequency clearly appears along with operational forcing frequencies for the measured strain (Figure 11(d)). The same phenomena were observed in the spectra measured using the accelerometers and strain gauges at ENE. This observation can be explained by the fact that various auxiliary machines, including oil pumps, cooling fans, and electric equipment, are switched on during operation and these machines increase the level of background vibration noise. This could be the reason for previous studies measuring the natural frequency with accelerometers after applying emergency stops $[60,61]$. In other words, a significant impact force would be induced in measuring the dynamic responses with the accelerometers [62]. In contrast, the spectra of strain show the natural frequency of the OWCS as well as frequencies associated with operation. Hence, it can be inferred that the measurement of strain using SHM is more effective than that of acceleration in characterizing the dynamic response or monitoring the evolution of natural frequencies of the OWCS because the frequencies of interest in this study are low frequencies. Note 


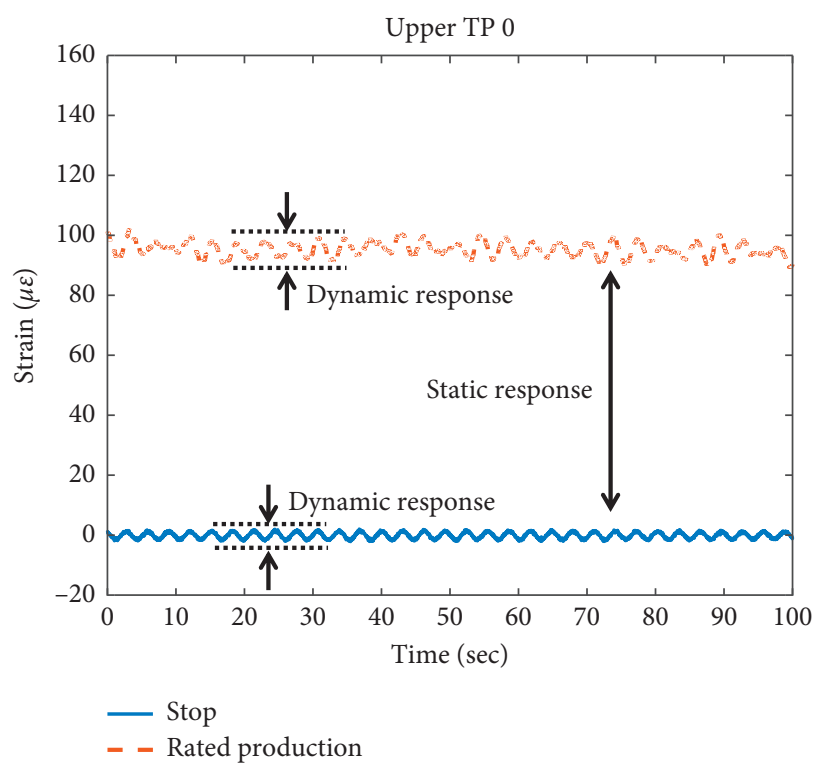

(a)

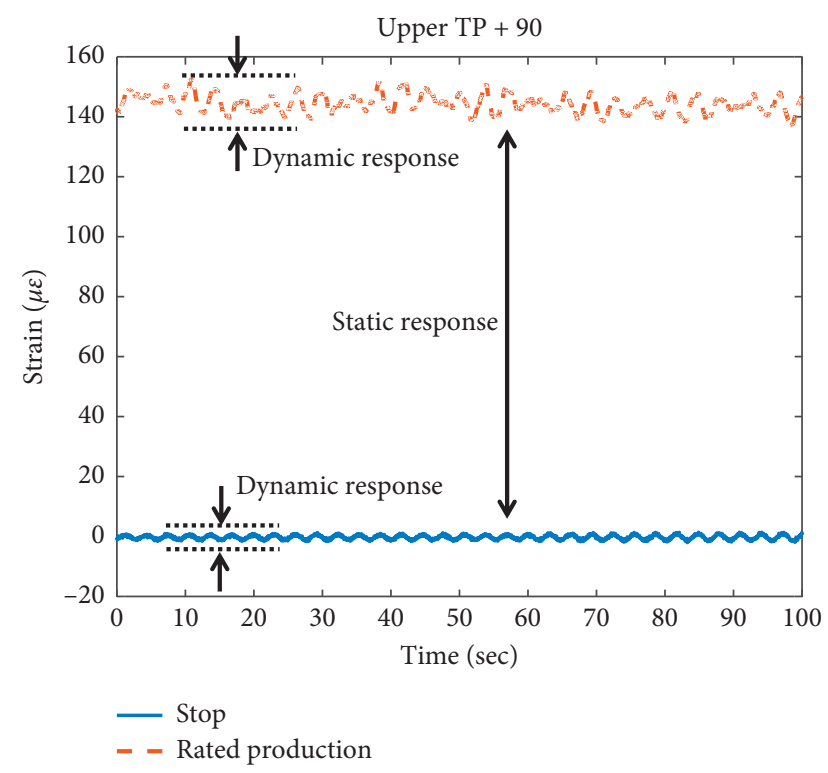

(b)

Figure 12: Static and dynamic responses measured from strain gauges.

that acceleration is proportional to the second derivative of the displacement with respect to time. This means that the acceleration is proportional to the square of the frequency in the frequency domain. Hence, the strain would be more apparent than the acceleration at low frequencies, but the acceleration would be larger than the strain at high frequencies.

In addition, the natural frequency under the rated operating condition $(0.33 \mathrm{~Hz})$ was slightly higher than that under the idling condition $(0.32 \mathrm{~Hz})$. This result is similar to that in [63], in which the first natural frequency predicted under the idling or stop conditions was slightly lesser than the measured frequency.

Several analytical approaches have been applied to elucidate the load dependency of the dynamic response, suggesting that the load dependency is primarily relevant to soil-pile interactions. One reason is that the static thrust force induced on the OWCS is significantly larger than the dynamic and cyclic force, as shown in Figure 12. This static load changes the friction angle of soil because of soil-pile interaction [64]. Another reason is that the equivalent stiffness of soil depends on the ratio of the diameter and length of embedding [60]. A relatively large ratio increases the bending stiffness of soil and piles, thereby increasing the first natural frequency with increasing load induced on the OWCS. This phenomenon can explain the slight increase in the natural frequency measured via SHM because the key characteristic of the suction bucket is the relatively large ratio of the diameter with respect to the length of embedding. Sediment transportation at the seabed also results in changes in the dynamic characteristics of the OWCS [61]. The scour depth depends on time because of aero- and hydrodynamic loads and thereby changes the eigenfrequency and modal damping. Compaction of the backfilled material occurs in the presence of waves, thereby inducing depth compaction. This phenomenon increases the friction angle and thereby shifts the eigenfrequency of the OWCS [64].

This interesting phenomenon might also be related to the pull in and out mechanism of the suction bucket. Under operational conditions, a significant thrust force, which is larger than the cyclic force, as shown in Figure 12, acts against the tip bearing force, which is a major supporting force of the suction bucket. Therefore, the equivalent stiffness of soil, including that of the suction bucket, increases. Note that the suction bucket provides two supporting forces for the structure. One is skin force between the soil and the skirt. The skin force is related to contact friction, which is influenced by pressure and type of soil. The contact friction is independent of the friction angle of the soil, which is defined by the inherent characteristics of the soil. The other is tip bearing force, which is the supporting force from the soil and is transmitted to the perimeter of the suction bucket. The contribution of the tip bearing force would be significant in the sense that the stiffness of the cap plays a critical role, as already shown in case studies. Moreover, the tip bearing force is governed by the friction angle, which is the same as shear strength.

\section{Conclusion}

This study evaluates the dynamic characteristics of an OWCS through simulation and experiments. An integrated framework was suggested to accurately model the seabed, including the soil, the skirt of a suction bucket, and the cap of a suction bucket. Full-scale experiments were also conducted for various stages under construction as well as under operation. The following conclusions can be drawn: 
(i) The stiffness of the cap of a suction bucket plays a critical role in predicting the natural frequencies of the OWCS. In particular, the contribution of the stiffness of the cap of the suction bucket is more significant when predicting dynamic responses of the substructure embedded in the seabed with suction buckets [65].

(ii) The strain dependency of the modulus of elasticity of the soil significantly affects the dynamic responses of the substructure. However, the effect of the strain dependency is limited with regard to predicting the dynamic responses of the entire structure. Hence, it can be inferred that the suction bucket embedded in soil should be designed with a focus on providing sufficient bearing capacity, whereas the substructure submerged in seawater should account for the dynamic responses of the OWCS and its substructure. Future work will include a systematic study using a 3D finite element model of the soil and the suction bucket to elucidate the strain with respect to depth and soil-pile interactions.

(iii) The natural frequency during the operational stage slightly differs from that during stop or idling conditions. This may be attributed to soil-pile interactions in the seabed. Specifically, the tip bearing force governed by thrust forces contributes to the evolution of the natural frequency depending on operational conditions such as stop and rated operation.

(iv) During operation, strain is more sensitive than acceleration for measuring the dynamic characteristics or long-term evolution of dynamic responses of the OWCS and its substructure. Hence, strain measurement can be used to predict the remaining useful life of the OWCS with the SHM system.

\section{Nomenclature}

$\begin{array}{ll}\text { CPT: } & \text { Cone penetration test } \\ \text { FEA: } & \text { Finite element analysis } \\ \text { FEM: } & \text { Finite element model } \\ \text { ENE: } & \text { East-northeast } \\ \text { FFT: } & \text { Fast Fourier transform } \\ \text { NNW: } & \text { North-northwest } \\ \text { OWCS: } & \text { Offshore wind conversion system } \\ \text { SHM: } & \text { Structural health monitoring } \\ \text { SPT: } & \text { Standard penetration test } \\ \text { PI: } & \text { Plasticity index } \\ \text { A: } & \text { Flexibility matrix } \\ \mathbf{A}_{\text {Seabed }}: & \text { Flexibility matrix of seabed } \\ \mathbf{A}_{\text {soil+suc.s }}: & \text { Flexibility matrix of soil and skirt of suction } \\ & \text { bucket } \\ \mathbf{A}_{\text {suc. }}: & \text { Flexibility matrix of cap of suction bucket } \\ \mathbf{F}_{\text {: }} & \text { Force vector } \\ \mathbf{K}_{\text {Seabed }}: & \text { Stiffness matrix of seabed } \\ \mathbf{U} & \text { Displacement vector } \\ \text { E: } & \text { Young's modulus }\end{array}$

$\begin{array}{ll}G: & \text { Secant shear modulus } \\ G_{\max }: & \text { Initial tangent shear modulus } \\ M_{*}: & \text { Moment in } * \text { direction } \\ S_{u}: & \text { Undrained shear strength } \\ V_{s}: & \text { Shear wave velocity } \\ f_{*}: & \text { Force in } * \text { direction } \\ q_{c}: & \text { Cone tip bearing resistance } \\ u_{*}: & \text { Displacement in } * \text { direction } \\ \theta_{*}: & \text { Angular displacement in } * \text { direction } \\ \phi: & \text { Internal friction angle } \\ \varepsilon: & \text { Strain } \\ \nu: & \text { Poisson's ratio } \\ \gamma_{d}: & \text { Unit weights for zero water content. }\end{array}$

\section{Data Availability}

The data used to support the findings of this study are available from the corresponding author upon request.

\section{Conflicts of Interest}

The authors declare that there are no conflicts of interest.

\section{Acknowledgments}

This study was partially supported by the Korea Institute of Energy Technology Evaluation and Planning (KETEP) (grant no. 20183010025730) (Development of diagnosis \& maintenance technologies for gear train of a wind turbine) funded by the Korean Ministry of Trade, Industry \& Energy (MOTIE) and a National Research Foundation of Korea (NRF) grant funded by the Korean government (MSIT) (no. 2020R1C1C1003829).

\section{References}

[1] G. M. Joselin Herbert, S. Iniyan, E. Sreevalsan, and S. Rajapandian, "A review of wind energy technologies," Renewable and Sustainable Energy Reviews, vol. 11, no. 6, pp. 1117-1145, 2007.

[2] C. Guo and D. Wang, "Frequency regulation and coordinated control for complex wind power systems," Complexity, vol. 2019, Article ID 8525397, 12 pages, 2019.

[3] M. Nasiri, S. Mobayen, and Q. M. Zhu, "Super-twisting sliding mode control for gearless PMSG-based wind turbine," Complexity, vol. 2019, Article ID 6141607, 15 pages, 2019.

[4] R. Jia, F. Ma, J. Dang, G. Liu, and H. Zhang, "Research on multidomain fault diagnosis of large wind turbines under complex environment," Complexity, vol. 2019, Article ID 2896850, 13 pages, 2019.

[5] E. Otaola, A. J. Garrido, J. Lekube, and I. Garrido, "A comparative analysis of self-rectifying turbines for the mutriku oscillating water column energy plant," Complexity, vol. 2019, Article ID 636904, 14 pages, 2019.

[6] S. V. Medina, J. A. Carta, and U. P. Ajenjo, "Performance sensitivity of a wind farm power curve model to different signals of the input layer of ANNs: case studies in the Canary islands," Complexity, vol. 2019, Article ID 2869149, 11 pages, 2019.

[7] Z. Wang, L. Zheng, W. Du et al., "A novel method for intelligent fault diagnosis of bearing based on capsule neural 
network," Complexity, vol. 2019, Article ID 6943234, 17 pages, 2019.

[8] S. L. Clainche and J. M. Vega, "Analyzing nonlinear dynamics via data-driven dynamic mode decomposition-like methods," Complexity, vol. 2018, Article ID 6920783, 21 pages, 2018.

[9] J. M. Torres and R. M. Aguilar, "Using deep learning to predict complex systems: a case study in wind farm generation," Complexity, vol. 2018, Article ID 9327536, 10 pages, 2018.

[10] C. Walsh, Offshore Wind in Europe-Key Trends and Statistics 2018, WindEurope, Brussels, Belgium, 2019.

[11] European Environment Agency, "Europe's onshore and offshore wind energy potential: an assessment of environmental and economic constraints," Technical Report No. 6, European Environment Agency, Copenhagen, Denmark, 2009.

[12] J. Ryue, K. Baik, and J.-H. Lee, "An analysis of horizontal deformation of a pile in soil using a continuum soil model for the prediction of the natural frequency of offshore wind turbines," The Journal of the Acoustical Society of Korea, vol. 35, no. 6, pp. 480-490, 2016.

[13] J. Jonkman, S. Butterfield, W. Musial, and G. Scott, "Definition of a $5 \mathrm{MW}$ reference wind turbine for offshore system development," Technical Report NREL/TP-500-38060, National Renewable Energy Laboratory, Golden, Co, USA, 2009.

[14] J. Ryue, K. Baik, and T.-R. Kim, "An analysis of horizontal deformation of a pile in soil using a beam-on-spring model for the prediction of the eigenfrequency of the offshore wind turbine," The Journal of the Acoustical Society of Korea, vol. 35, no. 4, pp. 261-271, 2016.

[15] Center for Wind Energy at James Madison University, Review of Options for Offshore Foundation Substructures, Center for Wind Energy at James Madison University, Harrisonburg, VA, USA, 2012.

[16] L. B. Ibsen, M. Liingaard, and S. A. Nielsen, Bucket Foundation, a Status, Copenhagen offshore wind, Copenhagen, Denmark, 2005.

[17] K.-Y. Oh, W. Nam, M. S. Ryu, J.-Y. Kim, and B. I. Epureanu, "A review of foundations of offshore wind energy convertors: current status and future perspectives," Renewable and Sustainable Energy Reviews, vol. 88, pp. 16-36, 2018.

[18] G. T. Houlsby and B. W. Byrne, "Design procedures for installation of suction caissons in clay and other materials," Proceedings of the Institution of Civil Engineers-Geotechnical Engineering, vol. 158, no. 2, pp. 75-82, 2005.

[19] G. T. Houlsby and B. W. Byrne, "Design procedures for installation of suction caissons in sand," Proceedings of the Institution of Civil Engineers-Geotechnical Engineering, vol. 158, no. 3, pp. 135-144, 2005.

[20] G. T. Houlsby, R. B. Kelly, J. Huxtable, and B. W. Byrne, "Field trials of suction caissons in sand for offshore wind turbine foundations," Géotechnique, vol. 56, no. 1, pp. 3-10, 2006.

[21] L. Wang, L. Yu, Z. Guo, and Z. Wang, "Seepage induced soil failure and its mitigation during suction caisson installation in silt," Journal of Offshore Mechanics and Arctic Engineering, vol. 136, 2014.

[22] J. P. Doherty, G. T. Houlsby, and A. J. Deeks, "Stiffness of flexible caisson foundations embedded in nonhomogeneous elastic soil," Journal of Geotechnical and Geoenvironmental Engineering, vol. 131, no. 12, pp. 1498-1508, 2005.

[23] M. Achmus, C. T. Akdag, and K. Thieken, "Load-bearing behavior of suction bucket foundations in sand," Applied Ocean Research, vol. 43, pp. 157-165, 2013.

[24] F. A. Villalobos, B. W. Byrne, and G. T. Houlsby, "An experimental study of the drained capacity of suction caisson foundations under monotonic loading for offshore applications," Soils and Foundations, vol. 49, no. 3, pp. 477488, 2009.

[25] B. W. Byrne and G. T. Houlsby, "Experimental investigations of the response of suction caissons to transient combined loading," Journal of Geotechnical and Geoenvironmental Engineering, vol. 130, no. 3, pp. 240-253, 2004.

[26] IEC 61400-3, Wind Turbines-Part 3: Design Requirements for Offshore Wind Turbines, IEC, Geneva, Switzerland, 2009.

[27] Det Norske Veritas, Design of Offshore Wind Turbine Structures," Offshore Standard DNV-OS-J101, DNV, Oslo, Norway, 2011.

[28] G. J. Rix and K. H. Stokoe, "Correlation of initial tangent modulus and cone penetration resistance," in Proceedings of the First International Symposium on Calibration Chamber Testing/ISOCCTI, pp. 351-362, New York, NY, USA, June 1991.

[29] Y.-H. Jung, K.-W. Lee, M.-M. Kim, H.-M. Kwon, and C.-K. Chung, "Evaluation of maximum shear modulus of silty sand in Songdo area in the west coast of Korea using various testing methods," Journal of the Korean Geotechnical Society, vol. 21, no. 9, pp. 65-75, 2005.

[30] P. K. Robertson, "Interpretation of cone penetration tests-a unified approach," Canadian Geotechnical Journal, vol. 46, no. 11, pp. 1337-1355, 2009.

[31] J. H. Schmertmann, "Static cone to compute static settlement over sand," Journal of the Soil Mechanics and Foundations Division, vol. 96, no. 3, pp. 1011-1043, 1970.

[32] G. Baldi, R. Bellotti, N. Ghionna, and M. Jamiolkowski, Stiffness of Sands from CPT, SPT and DMT-A Critical Review in Penetration Testing in the UK," Penetration Testing in the UK No. 42, The Institution of Civil Engineers, Birmingham, UK, 1989.

[33] P. K. Robertson, D. J. Woeller, and W. D. L. Finn, "Seismic cone penetration test for evaluating liquefaction potential under cyclic loading," Canadian Geotechnical Journal, vol. 29, no. 4, pp. 686-695, 1992.

[34] C. E. Fear and P. K. Robertson, "Estimating the undrained strength of sand: a theoretical framework," Canadian Geotechnical Journal, vol. 32, no. 5, pp. 859-870, 1995.

[35] C. E. Wride, P. K. Robertson, K. W. Biggar et al., "Interpretation of in situ test results from the CANLEX sites," Canadian Geotechnical Journal, vol. 37, no. 3, pp. 505-529, 2000.

[36] R. D. Andrus, N. P. Mohanan, P. Piratheepan, B. S. Ellis, and T. L. Holzer, "Predicting shear-wave velocity from cone penetration resistance," in Proceedings of the 4th International Conference on Earthquake Geotechnical Engineering 2007, pp. 25-28, Thessaloniki, Greece, June 2007.

[37] R. Dobry, "Comparison between clean sand liquefaction charts based on penetration resistance and shear wave velocity," in Proceedings of the 5th International Conference on Recent Advances in Geotechnical Earthquake Engineering and Soil Dynamics 2010, San Diego, CA, USA, 2010.

[38] L. Paoletti, Y. Hegazy, S. Monaco, and R. Piva, "Prediction of shear wave velocity for offshore sands using cpt data-Adriatic sea," in Second International Symposium on Cone Penetration Testing 2010, pp. 1-8, Huntington Beach, CA, USA, 2010.

[39] M. Karray, G. Lefebvre, Y. Ethier, and A. Bigras, "Influence of particle size on the correlation between shear wave velocity and cone tip resistance," Canadian Geotechnical Journal, vol. 48, no. 4, pp. 599-615, 2011.

[40] C.-G. Sun, C.-S. Cho, M. Son, and J. S. Shin, "Correlations between shear wave velocity and in-situ penetration test 
results for Korean soil deposits," Pure and Applied Geophysics, vol. 170, no. 3, pp. 271-281, 2013.

[41] KAIST, A Report to Estimate Deformation Modulus of Seabed for Seashore Wind Turbine Construction \& Commercialization Embedded Suction Bucket Support Structure, KAIST, Daejeon, Republic of Korea, 2015.

[42] M. Vucetic and R. Dobry, "Effect of soil plasticity on cyclic response," Journal of Geotechnical Engineering, vol. 117, no. 1, pp. $89-107,1991$

[43] P. Simonini and S. Cola, "Use of piezocone to predict maximum stiffness of Venetian soils," Journal of Geotechnical and Geoenvironmental Engineering, vol. 126, no. 4, pp. 378-382, 2000.

[44] A. Jaime and M. P. Romo, "The Mexico earthquake of September 19, 1985-correlations between dynamic and static properties of Mexico city clay," Earthquake Spectra, vol. 4, no. 4, pp. 787-804, 1988.

[45] P. W. Mayne and G. J. Rix, "Correlations between shear wave velocity and cone tip resistance in natural clays," Soils and Foundations, vol. 35, no. 2, pp. 107-110, 1995.

[46] M. Long and S. Donohue, "Characterization of Norwegian marine clays with combined shear wave velocity and piezocone cone penetration test (CPTU) data," Canadian Geotechnical Journal, vol. 47, no. 7, pp. 709-718, 2010.

[47] L. Tonni and P. Simonini, "Shear wave velocity as function of cone penetration test measurements in sand and silt mixtures," Engineering Geology, vol. 163, pp. 55-67, 2013.

[48] G. Cai, A. J. Puppala, and S. Liu, "Characterization on the correlation between shear wave velocity and piezocone tip resistance of Jiangsu clays," Engineering Geology, vol. 171, pp. 96-103, 2014

[49] S. S. Rao, Mechanical Vibrations, Prentice-Hall, Upper Saddle River, NJ, USA, 5th edition, 2011.

[50] A. Klimchik, A. Pashkevich, S. Caro, and D. Chablat, "Stiffness matrix of manipulators with passive joints: computational aspects," IEEE Transactions on Robotics, vol. 28, no. 4, pp. 955-958, 2012.

[51] M. Jureczko, M. Pawlak, and A. Mężyk, "Optimisation of wind turbine blades," Journal of Materials Processing Technology, vol. 167, no. 2-3, pp. 463-471, 2005.

[52] K.-Y. Oh, J.-Y. Kim, J.-S. Lee, and K.-W. Ryu, "Wind resource assessment around Korean Peninsula for feasibility study on $100 \mathrm{MW}$ class offshore wind farm," Renewable Energy, vol. 42, pp. 217-226, 2012.

[53] M. S. Ryu, J. S. Lee, D. J. Kwag, and S. Bang, "Comparison of two meteorological tower foundations for off-shore wind turbines," in Proceedings of the 26th International Ocean and Polar Engineering Conference, Rhodes, Greece, July 2016.

[54] H.-G. Moll, F. Vorpahl, and H.-G. Busmann, "Dynamics of support structures for offshore wind turbines in fully-coupled simulations-influence of water added mass on jacket mode shaper, natural frequencies and loads," in Proceedings of the European Wind Energy Conference and Exhibition, Warsaw, Poland, Aprril 2010.

[55] Det Norske Veritas, Modeling and Analysis of Marine Operations, DNV, Oslo, Norway, 2011.

[56] D. J. Ewins, Modal Testing Theory, Practice and Application, Research Studies Press Ltd., Boston, MA, USA, 2nd edition, 2000.

[57] K.-Y. Oh, J.-Y. Kim, J.-K. Lee, M.-S. Ryu, and J.-S. Lee, “An assessment of wind energy potential at the demonstration offshore wind farm in Korea," Energy, vol. 46, no. 1, pp. 555-563, 2012.
[58] J. H. Atkinson and G. Sallfors, "Experimental determination of soil properties," in Proceedings of the 10th ECSMFE 1991, vol. 3, Florence, Italy, 1991.

[59] W. Nam, K.-Y. Oh, and B. I. Epureanu, "Evolution of the dynamic response and its effects on the serviceability of offshore wind turbines with stochastic loads and soil degradation," Reliability Engineering \& System Safety, vol. 184, pp. 151-163, 2019.

[60] L. V. Andersen, M. J. Vahdatirad, M. T. Sichani, and J. D. Sørensen, "Natural frequencies of wind turbines on monopile foundations in clayey soils-a probabilistic approach," Computers and Geotechnics, vol. 43, pp. 1-11, 2012.

[61] M. Damgaard, L. B. Ibsen, L. V. Andersen, and J. K. F. Andersen, "Cross-wind modal properties of offshore wind turbines identified by full scale testing," Journal of Wind Engineering and Industrial Aerodynamics, vol. 116, pp. 94108, 2013.

[62] R. Shirzadeh, C. Devriendt, M. A. Bidakhvidi, and P. Guillaume, "Experimental and computational damping estimation of an offshore wind turbine on a monopile foundation," Journal of Wind Engineering and Industrial Aerodynamics, vol. 120, pp. 96-106, 2013.

[63] M. B. Zaaijer, "Foundation modelling to assess dynamic behaviour of offshore wind turbines," Applied Ocean Research, vol. 28, no. 1, pp. 45-57, 2006.

[64] R. Rubak and J. Thirstrup Petersen, "Monopile as part of aeroelastic wind turbine simulation code," in Proceedings of Copenhagen Offshore Wind, Hellerup, Denmark, 2005. 